\title{
TRATAMENTO DE MANIFESTAÇÃO DE CLIENTES E SINISTROS DA ARCELORMITTAL BRASIL PLANOS NO SAP*
}

\author{
Cristiane Lazzaro Barbosa ${ }^{1}$ \\ Uarlem José de Faria Oliveira ${ }^{2}$ \\ Wellington Medeiros da Silva ${ }^{3}$
}

\section{Resumo}

Visando a melhoria contínua no atendimento a seus Clientes, além de garantir a confiabilidade e rastreabilidade do processo de tratamento das manifestações de seus clientes e dos sinistros ocorridos com os produtos adquiridos, a ArcelorMittal Brasil Planos investe na atualização do sistema que suporta este processo e na convergência para o SAP. O Projeto, denominado QM Comercial, utilizou os módulos QM, DMS, SD e WF do SAP ECC para implementar a solução de registro, documentação, elaboração do parecer com a análise de várias áreas/unidades da empresa e a orquestração das atividades dos processos comerciais/financeiros de conclusão da reclamação/sinistro. Todas as etapas com rastreabilidade e controle de tempo de resposta das áreas envolvidas.

Palavras-chave: SAP-QM; Workflow; Reclamação de cliente; Qualidade do produto; Sinistros.

\section{TREATMENT OF CUSTOMER CLAIMS USING SAP IN ARCELORMITTAL BRAZIL - FLAT SEGMENT}

\begin{abstract}
To guarantee the continuous improvement in the process of customer services, and to ensure the reliability and traceability of the process of treatment customers claims and the ocurrences with the products purchased, ArcelorMittal Brazil - Flat segment invests in system upgrade that supports this process and convergence to SAP. The project, called QM Commercial, used the SAP ECC modules: QM, DMS, SD and WF to implement the solution of registry, documentation, preparing the claim verdict with the analysis of any areas or business units and the orchestration of all business processes activities to finalize the claim. All stages with traceability and response time control of the areas involved.
\end{abstract}

Keywords: SAP-QM; Workflow; Customer compliants; Product quality; Casualty.

Analista de TI, ArcelorMittal Tubarão, Vitória, ES, Brasil.

Especialista de Assistência Técnica, ArcelorMittal Tubarão, Vitória, ES, Brasil.

Analista de Vendas, ArcelorMittal Tubarão, Vitória, ES, Brasil. 


\section{INTRODUÇÃO}

Existem diversos itens que clientes e fornecedores devem seguir e obedecer para concretizar qualquer venda de produto e/ou serviço. Dentre elas, podemos citar:

- Requisitos dos clientes, normas técnicas e regulamentadoras

- Condições e Restrições dos Modais de Transporte

- Condições de Mercado e Financeiras

- Regras de Compliance

- Destinação dos produtos

- Armazenamento e Transporte

- Restrições das plantas produtivas

- Características do material e dos pedidos dos clientes.

Qualquer uma dessas variáveis ou outras envolvidas nos processos de vendas e entrega do produto para o cliente podem sofrer uma anomalia que ocasione uma reclamação de cliente ao fornecedor do produto.

A ArcelorMittal possui um processo e áreas na empresa que são destinadas para tratar estas manifestações dos clientes e a tecnologia da informação provê soluções para suportá-los.

As principais áreas envolvidas são assistência técnica, comercial, controle de qualidade e logística das diversas unidades do segmento de Produtos Planos da empresa.

O cenário anterior dos sistemas que suportavam este processo se apresentava desintegrado e gerando muito retrabalho para os profissionais envolvidos no tratamento das manifestações dos clientes, inclusive com probabilidade de duplicação e informação incorreta de dados dos pedidos dos clientes.

A figura 1, apresenta as soluções de sistemas que eram utilizadas em cada unidade do segmento de Aços Planos da ArcelorMittal.

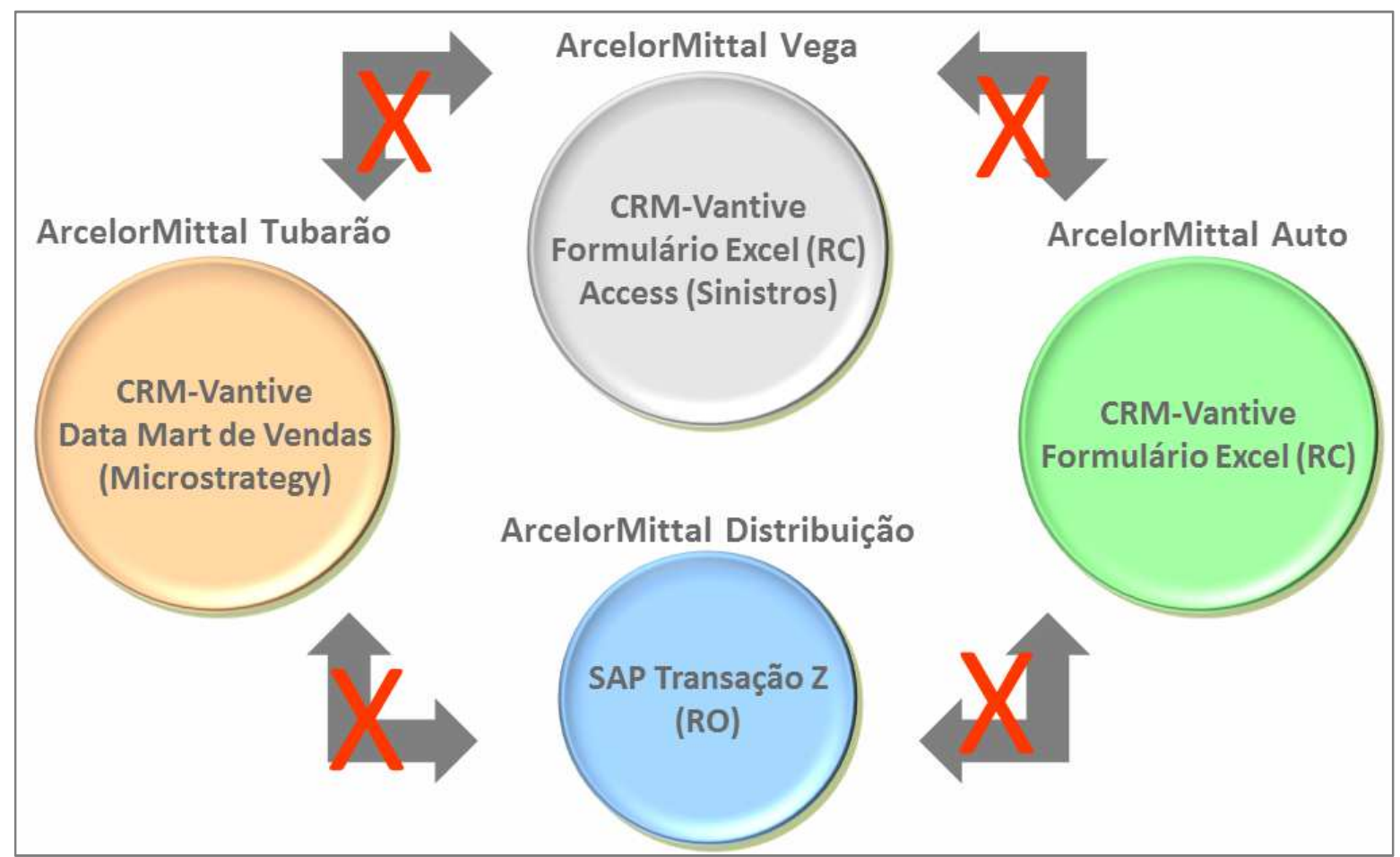

Figura 1 - Cenário Anterior de Sistemas 
Diante do contexto de negócio e sistemas exposto, o projeto denominado "QM Comercial" foi conduzido com o principal objetivo de disponibilizar solução padronizada para o Segmento de Aços Planos da ArcelorMittal Brasil no SAP para suportar os processos de tratamento das manifestações de clientes e sinistros.

Os principais desafios do projeto foram:

- Proporcionar análise integrada das manifestações dos clientes nas unidades de Planos garantindo a rastreabilidade do processo

- Garantir a integração com o módulo de vendas e faturamento suportando as diversas modalidades de vendas e utilizando o rastreamento dos lotes de produto ao longo da cadeia

- Garantir o bom gerenciamento da mudança nas unidades de negócio tendo em vista que o Go-Live deve ser em um mesmo momento

- Desenhar solução de sistema flexível para absorver as alterações de processos e seus responsáveis de forma ágil e com baixo custo de manutenção

O escopo de atuação do projeto, e suas consequentes entregas, estão descritos de forma visual através da WBS (work breakdown structure) na figura 2.

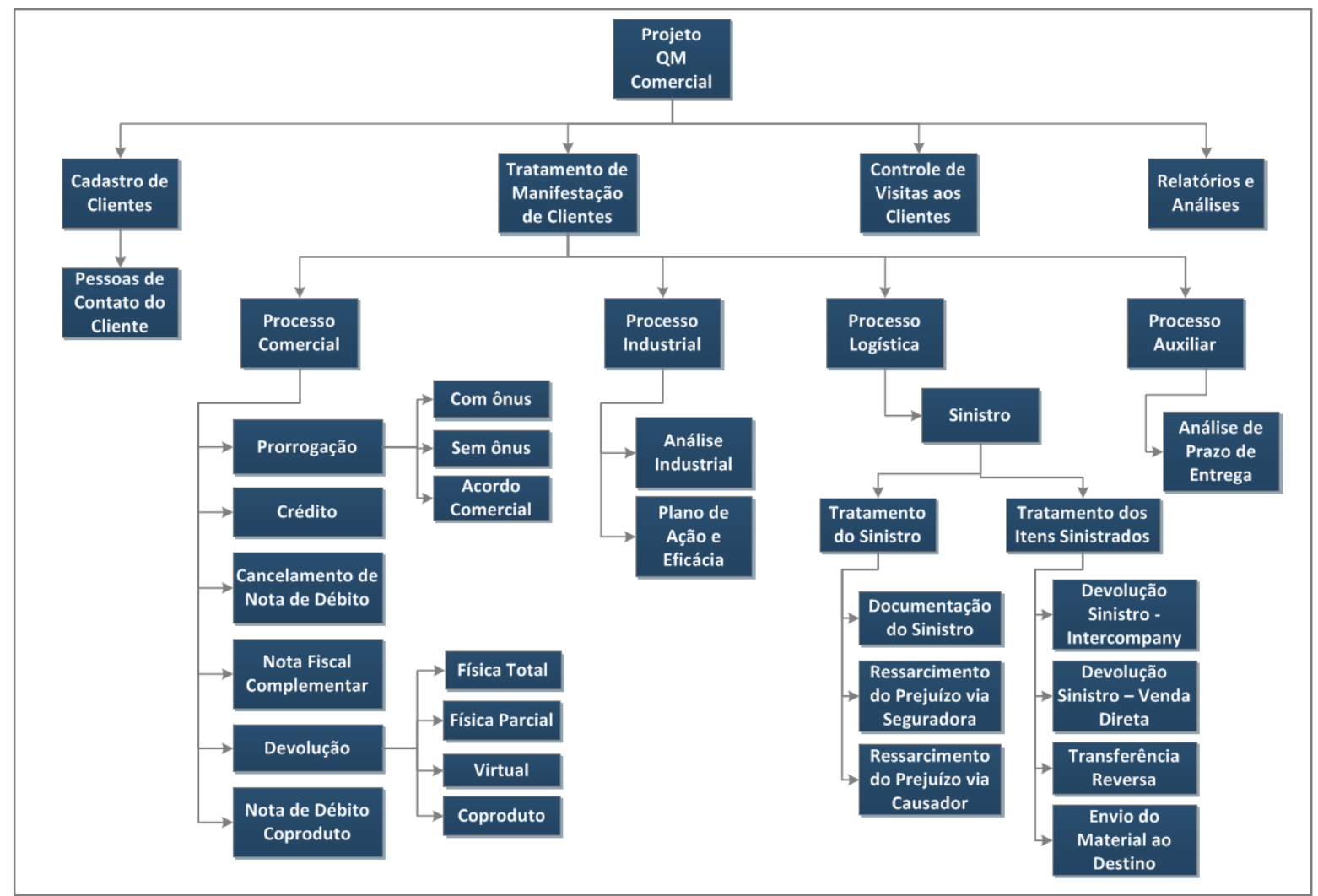

Figura 2 - WBS (Work Breakdown Structure) do Projeto

\section{MATERIAIS E MÉTODOS}

O projeto foi gerenciado seguindo a Metodologia de Gerenciamento de Projetos baseada nas melhores práticas descritas pelo PMBOK do PMI (Project Management Institute) e adotada pela área de $\mathrm{TI}$ da ArcelorMittal Brasil. As etapas para o gerenciamento de projetos estão descritas: 


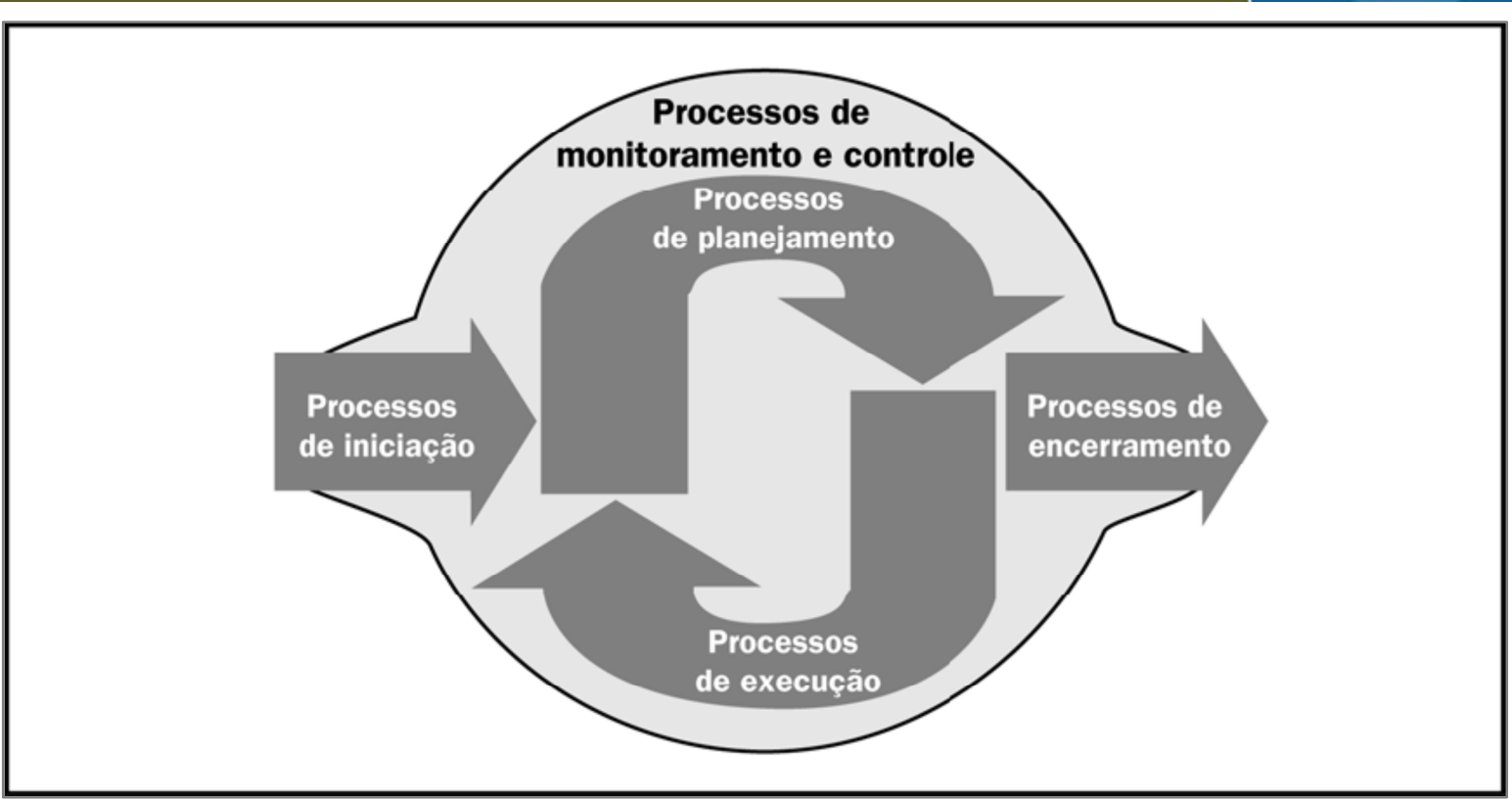

Figura 3- Etapas para o gerenciamento de projetos

\subsection{Etapa de Iniciação}

A etapa de iniciação é constituída pelos processos que facilitam a autorização formal para iniciar um novo projeto. São desenvolvidas descrições claras dos objetivos do projeto, incluindo as razões pelas quais um projeto específico se constitui na melhor solução para satisfazer os requisitos. A documentação dessa decisão também contém uma descrição básica do escopo do projeto, das entregas, da duração do projeto e uma previsão dos recursos para a análise de investimentos da organização.

\subsection{Etapa de Planejamento}

A equipe de gerenciamento de projetos usa a etapa de planejamento para planejar e gerenciar um projeto bem-sucedido para a organização. Os processos de planejamento desenvolvem o plano de gerenciamento do projeto. Esses processos também identificam, definem e amadurecem o escopo, o custo e agendam as atividades que ocorrem dentro do projeto.

\subsection{Etapa de Execução}

A etapa de execução é constituída pelos processos usados para realizar o trabalho definido no plano de gerenciamento do projeto a fim de cumprir os requisitos do projeto. Este grupo de processos envolve a coordenação das pessoas e dos recursos, além da integração e da realização das atividades do projeto de acordo com o plano de gerenciamento do projeto. Este grupo de processos também aborda o escopo definido na declaração do escopo do projeto e implementa as alterações aprovadas.

\subsection{Etapa de Monitoramento e Controle}

A etapa de monitoramento e controle é constituída pelos processos realizados para acompanhar o andamento do projeto, de forma que possíveis problemas possam ser 
identificados no momento adequado e que possam ser tomadas ações corretivas, quando necessário, para controlar a execução do projeto. O principal benefício desta etapa é que o desempenho do projeto é acompanhado e medido regularmente para identificar variações em relação ao plano de gerenciamento do projeto. A etapa de monitoramento e controle também inclui o controle de alterações e a recomendação de ações preventivas, antecipando possíveis problemas.

\subsection{Etapa de Encerramento}

A etapa de encerramento inclui os processos usados para finalizar formalmente todas as atividades de um projeto, entregar o produto terminado para outros ou encerrar um projeto cancelado. Esta etapa, quando terminada, verifica se os processos definidos estão terminados dentro de todas as etapas para encerrar o projeto e estabelece formalmente que o projeto está concluído.

Além destas etapas, o projeto também é gerenciado por área de conhecimento conforme a seguir:

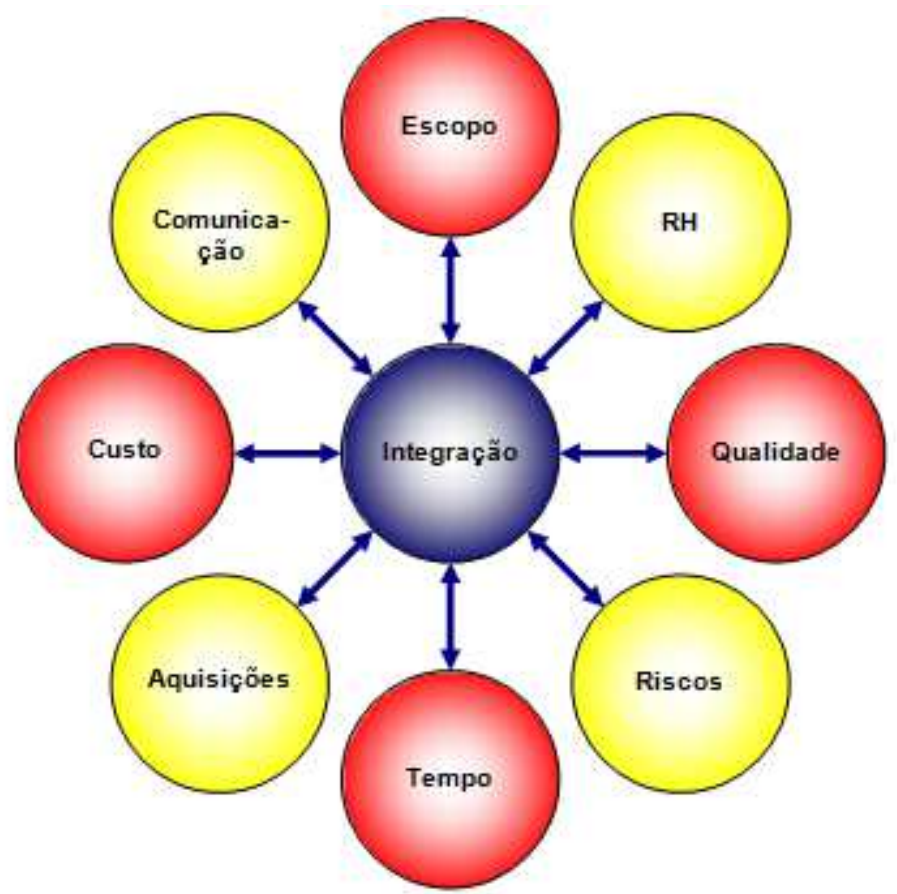

Figura 4 - Área de Conhecimento no gerenciamento de projetos

- Integração: descreve os processos e as atividades que integram os diversos elementos do gerenciamento de projetos, que são identificados, definidos, combinados, unificados e coordenados dentro dos grupos de processos de gerenciamento de projetos. Ele consiste nos processos de gerenciamento de projetos: desenvolver project charter, gerenciamento preliminar de escopo, autorização da etapa (Planejamento, Execução e Encerramento), reunião de kickoff, desenvolver e integrar o plano do projeto, execução do plano do projeto, monitorar e controlar o trabalho do projeto, controle integrado de alterações e encerrar o projeto.

- Escopo: descreve os processos envolvidos na verificação de que o projeto inclui todo o trabalho necessário, e apenas o trabalho necessário, para que seja concluído com sucesso. Ele consiste nos processos de gerenciamento 
de projetos: planejamento e definição do escopo do projeto, revisão da WBS, verificação do escopo e controle do escopo.

- Tempo: descreve os processos relativos ao término do projeto no prazo correto. Ele consiste nos processos de gerenciamento de projetos: detalhamento das atividades, elaboração do cronograma e controle do cronograma.

- Custo: descreve os processos envolvidos em planejamento, estimativa, orçamentação e controle de custos, de modo que o projeto termine dentro do orçamento aprovado. Ele consiste nos processos de gerenciamento de projetos: detalhamento do orçamento e controle de custos.

- Qualidade: descreve os processos envolvidos na garantia de que o projeto irá satisfazer os objetivos para os quais foi realizado. Ele consiste nos processos de gerenciamento de projetos: planejamento da qualidade, realizar a garantia da qualidade e controle da qualidade.

- Recursos Humanos: descreve os processos que organizam e gerenciam a equipe do projeto. Ele consiste nos processos de gerenciamento de projetos: planejamento de recursos humanos, contratar ou mobilizar a equipe do projeto, desenvolver a equipe do projeto e gerenciar o time do projeto.

- Comunicação: descreve os processos relativos à geração, coleta, disseminação, armazenamento e destinação final das informações do projeto de forma oportuna e adequada. Ele consiste nos processos de gerenciamento de projetos: planejamento da comunicação, distribuição da informação, relatório de desempenho e comunicação.

- Riscos: descreve os processos relativos à realização do gerenciamento de riscos em um projeto. Ele consiste nos processos de gerenciamento de projetos: planejamento de riscos e monitoramento e controle de riscos.

- Aquisições: descreve os processos que compram ou adquirem produtos, serviços ou resultados, além dos processos de gerenciamento de contratos. Ele consiste nos processos de gerenciamento de projetos: planejar compras e aquisições, solicitar respostas de fornecedores, selecionar fornecedores, administração de contratos e encerramento do contrato.

As atividades referentes ao desenvolvimento do produto no SAP seguiu à Metodologia ASAP proposta pela empresa SAP, conforme roadmap descrito abaixo:

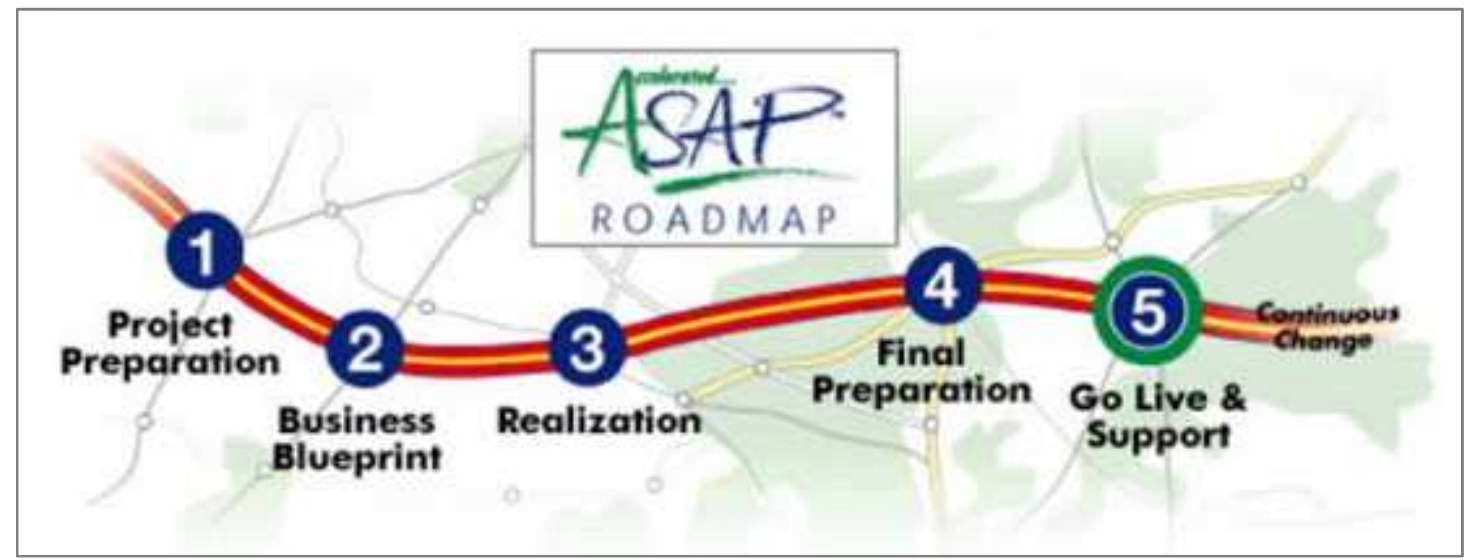

Figura 5 - ASAP Roadmap 


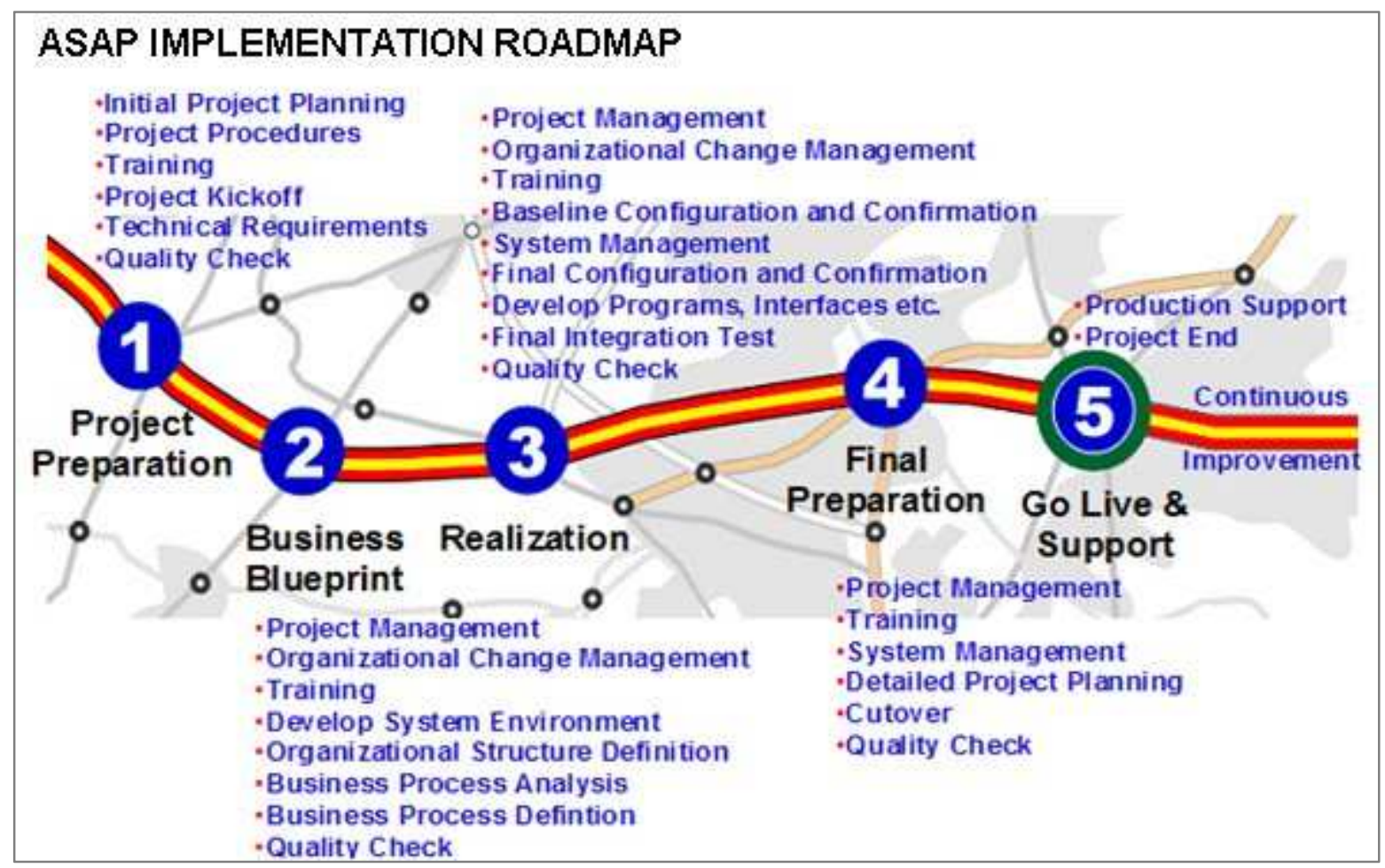

Figura 6 - ASAP Implementation Roadmap

\section{RESULTADOS E DISCUSSÃO}

Utilizando principalmente os módulos QM (Quality Management), SD (Sales and Distribution), WF (Workflow) e DMS (Document Management System) da solução do ERP SAP, a solução sistêmica visa automatizar e garantir rastreabilidade do tratamento das reclamações e sinistros dos clientes.

O desenho da arquitetura da solução no SAP está descrito Figura 7 na qual são indicadas as funcionalidades utilizadas em cada módulo.

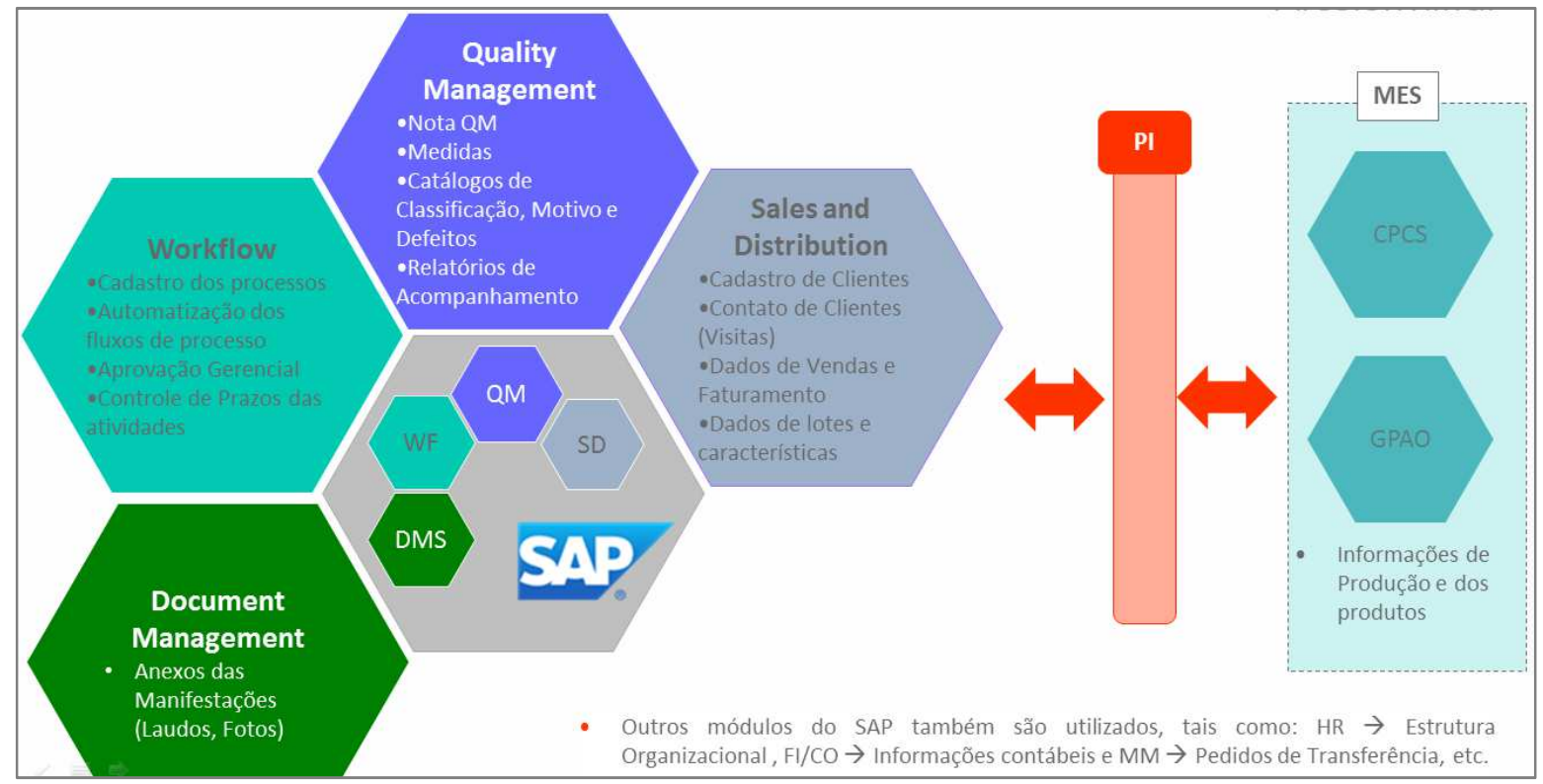

Figura 7 - Desenho da solução no SAP 
Como uma forma da aplicação destas funcionalidades no SAP, a análise do problema é gerada e associada aos dados do lote reclamado bem como aos dados de vendas e faturamento do mesmo.

Ocorre toda uma análise e classificação do defeito e motivo da reclamação gerando um parecer da procedência e possivelmente um plano de ação para tratar sua resolução da causa raiz.

A figura 8 descreve a relação entre essas atividades no SAP.

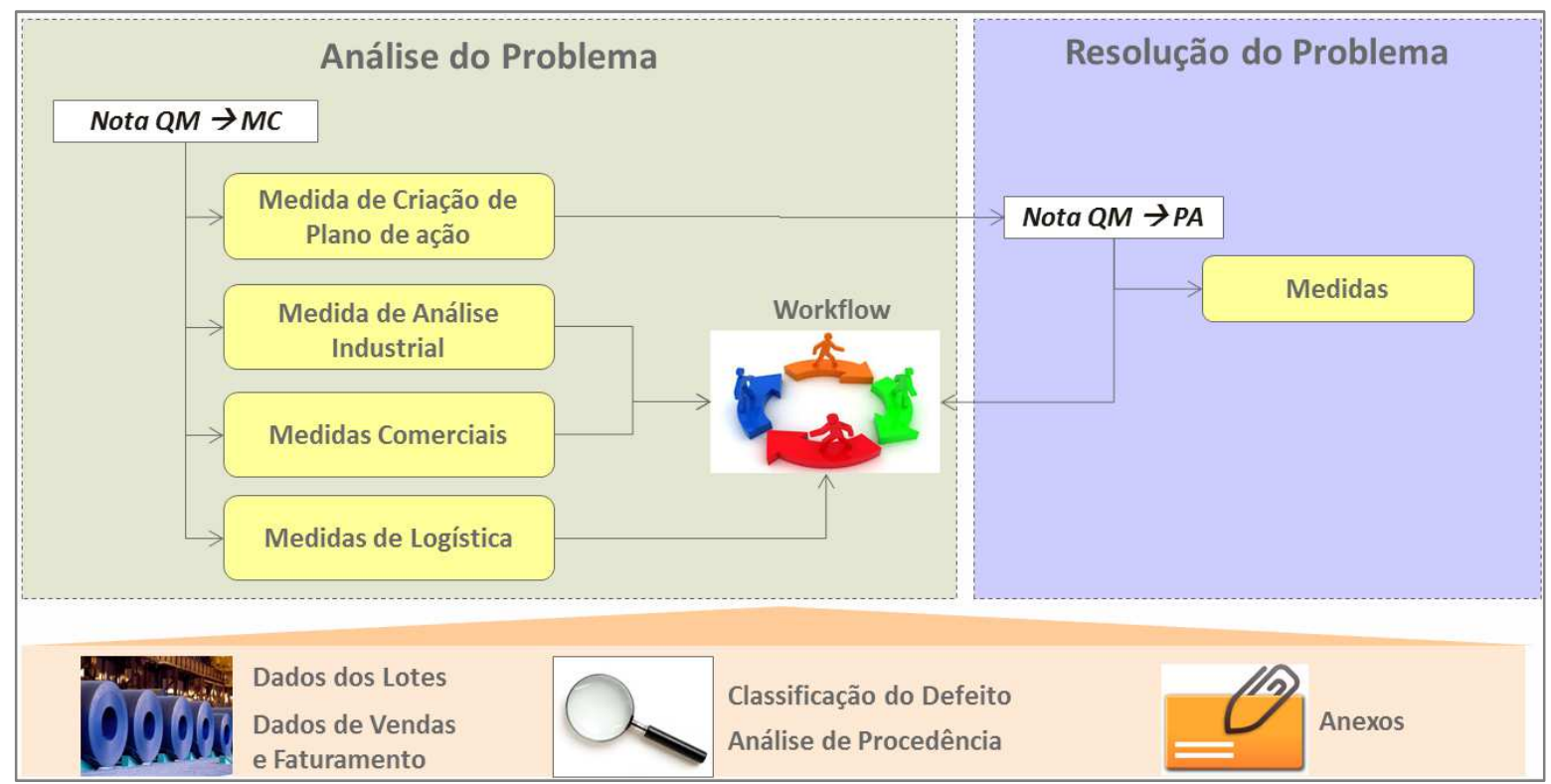

Figura 8 - Aplicação do Desenho da solução no SAP

Para cada reclamação do cliente podem ser necessárias ações comerciais, logísticas ou técnico-industriais. Todas essas ações são orquestradas por workflow que é responsável por rotear as atividades para os grupos de pessoas envolvidos em seu tratamento e mensurar o tempo de cada um na visão do tempo total de resolução.

A figura 9 apresenta a solução desenha no Workflow SAP que permite a flexibilização das atividades dos processos bem como os responsáveis pelo mesmo. 


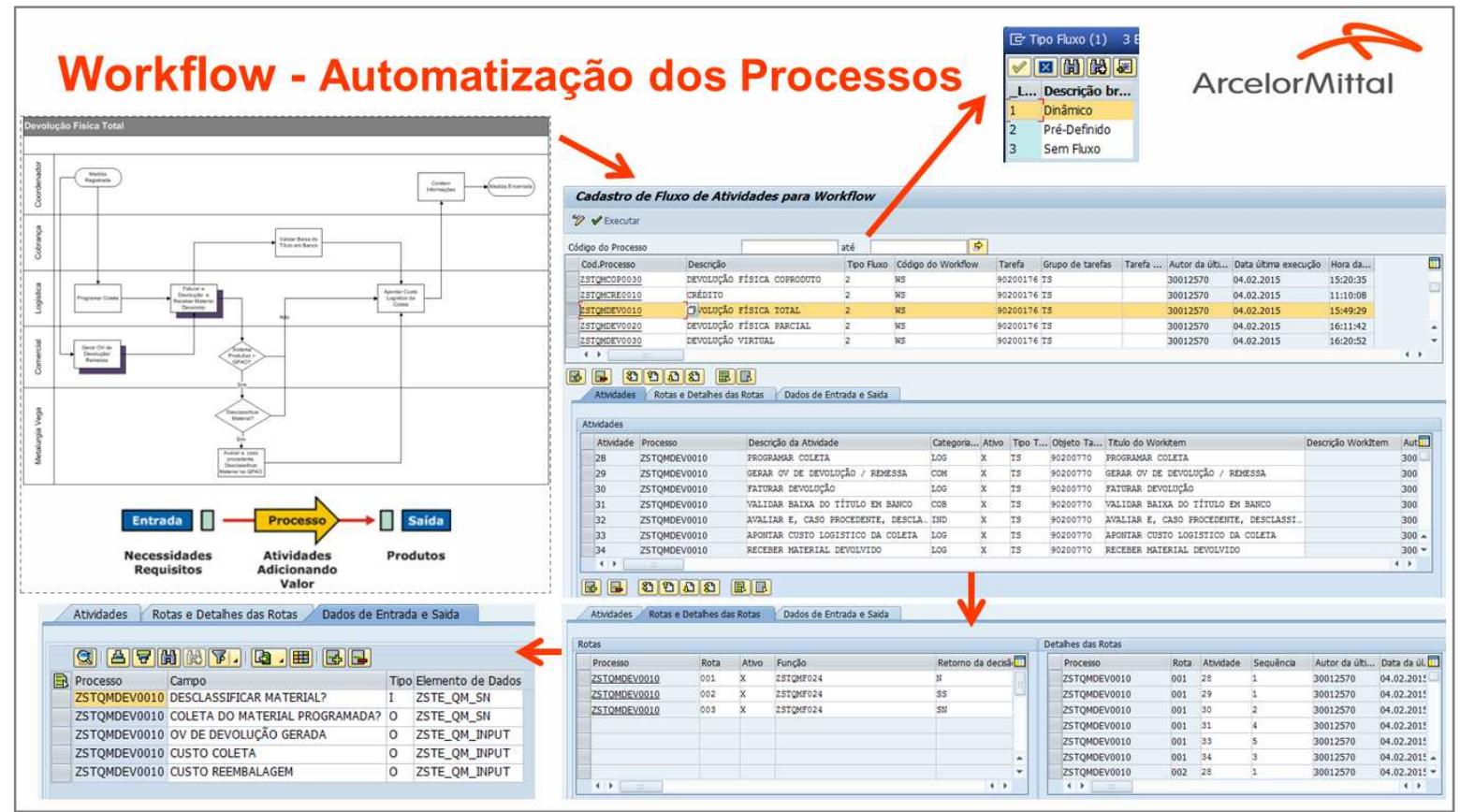

Figura 9 - Automatização dos Processos via Workflow SAP

A solução adotada foi uma evolução da solução implantada há aproximadamente 10 anos no setor de Arames da ArcelorMittal, cujo sucesso da implantação já foi obtido.

\section{CONCLUSÃo}

Após a implantação do projeto os benefícios esperados e, alguns já realizados, para o negócio e para a TI são principalmente:

- Rastreabilidade do processo garantindo aderência às exigências das normas certificadoras e do mercado.

- Potencial ganho de redução de tempo no tratamento das manifestações dos clientes

- Padronização destes processos para as unidades da ArcelorMittal Planos Brasil com convergência para o SAP

- Redução de retrabalho na análise das manifestações evitando a duplicação de informações entre os sistemas e erros de input de dados

- Automatização de aprovações gerenciais e de processos

- Desativação de sistemas 4 legados (CRM-Vantive, DataMart de Vendas, planilhas Excel de RC e Access de Gestão de Sinistro 